\title{
LA PESADILLA DE DESCARTES
}

\author{
DESCARTES' NIGHTMARE
}

\section{Jesús GONZÁLEZ REQUENA}

Universidad Complutense de Madrid

Resumen: En el presente trabajo sostenemos que en el núcleo de la escritura -y de la pasión- de ese filósofo esencial de la Modernidad que fue Descartes se halla presente, literalmente, una pesadilla. Y sostenemos, igualmente, que la índole de esa pesadilla permite dilucidar la contradicción que se manifiesta presente en la expresión "sujeto moderno".

Para ello, procedemos al análisis de las líneas mayores de la filosofía cartesiana: su radical critica de las filosofías anteriores, su voluntad de construir el método de la ciencia, la adopción de las matemáticas y la geometría como disciplinas de referencia en las que logra aislar la autonomía y la productividad del significante, el papel de la duda y el momento negativo que la caracteriza, la construcción de un modelo del sujeto concebido como máquina de inteligibilidad... Finalmente, analizamos el famoso sueño de Descartes como una pesadilla directamente vinculada al devenir de su filosofía y reveladora tanto de la personal experiencia dramática del filósofo como de los impases del sujeto contemporáneo.

Palabras clave: Descartes, sueño, pesadilla, sujeto, filosofía.

Abstract: In the present paper we argue that in the core of the writing -and the passion- of that essential philosopher of Modernity that was Descartes occurs, literally, a nightmare. And we also maintain that the nature of this nightmare allows us to elucidate the contradiction that is present in the expression "modern subject".

To do this, we proceed to an analysis of the main lines of Cartesian philosophy: it's radical criticism of previous philosophies, it's willingness to construct a scientific method, the relegation of mathematics and geometry to disciplines of reference that are robbed of any significant autonomy or productivity, the role of doubt and the negative force that characterizes it, the construction of a model of the subject conceived as a machine of intelligibility... Finally, we analyze the famous dream of Descartes as a nightmare directly linked to the evolution of his philosophy wich reveals as much about the dramatic personal experience of the philosopher as the impasses of the contemporary subject.

Keywords: Descartes, dream, nightmare, subject, philosophy. 


\section{- El sujeto moderno?}

$\boldsymbol{6}$ ¿El sujeto moderno? ¿No hay una cierta contradicción en esta expresión? ¿No hay, en el proyecto de la Modernidad, una dificultad específica para articular eso que constituye la radical individualidad del ser?

Propondremos, en lo que sigue, una manera de pensar esa dificultad, resumida en una frase: el sujeto moderno participa de la pesadilla de Descartes. Pero no la escuchen como metafórica: voy a tratar de mostrar cómo, en el núcleo de la escritura -y de la pasión- de ese filósofo esencial de la Modernidad que fue Descartes se halla presente, literalmente, una pesadilla.

Pero antes de ello, para poder comprender el contexto de su emergencia, conviene que situemos los términos esenciales de ese racionalismo cartesiano que prefigura y modela los ejes principales del proyecto de la Modernidad.

\section{Romper con la dominancia de los discursos filosóficos}

Una buena manera de comenzar esa tarea es prestar atención al subtítulo del Discurso del Método: Para conducir la razón y buscar la verdad en las ciencias.

Porque se trataba precisamente de eso, Descartes partía de una crítica radical de la filosofía:

Las ciencias toman sus principios de la filosofía y yo en ésta hasta entonces nada de cierto había encontrado. (Descartes, [1637] 1972: 17) 15) ${ }^{1}$.

Nada por raro y extravagante ha dejado de ser defendido por algún filosofo. (Descartes, [1637] 1972:

La novedad de la filosofía cartesiana estriba así en su voluntad de romper con la dominancia en el campo del saber de los discursos filosóficos que obstaculizaban el progreso de las ciencias ${ }^{2}$. Se trataba, en suma, de eliminar las trabas que las doctrinas filosóficas ponían al desarrollo del emergente discurso de la ciencia que, en la primera mitad del siglo XVII, había alcanzado ya una presencia notable.

Y una presencia física, cuya pujanza se manifestaba en las máquinas que se demostraba capaz de introducir en el mundo.

\section{Epistemología: Método del discurso de la ciencia}

Conviene entender en toda su extensión la originalidad de estos nuevos principios de la filosofía ${ }^{3}$ a cuya formulación se entregara Descartes. Porque la ciencia está ya ahí, en pleno siglo XVII, demostrando, a pesar de todo, su pujanza, su poder, sus grandes resultados (Descartes, 1637: 9),

\footnotetext{
${ }^{1}$ Y también, p. 11: la filosofia [...] la habian cultivado las inteligencias más elevadas de todos los siglos, y a pesar de ello nada quedaba fuera de discusión [...] (Descartes, 1637: 11)

${ }^{2}$ Las [...] ciencias tomaban sus principios de la filosofía, y sobre fundamentos tan poco sólidos nada podía construirse. (Descartes, 1637: 12)

${ }^{3}$ Lo más racional era establecer los principios de la filosofía [...] (Descartes, 1637: 17)
} 
Descartes está en condiciones de hacer su epistemología: no aspira a conformar una nueva doctrina filosófica sino, por el contrario, a configurar el Método del discurso de la ciencia.

Por eso, su obra puede ser considerada como el movimiento inaugural de la epistemología en el sentido moderno del término, es decir, como una filosofía abocada al estudio de las condiciones -de las garantías de rigor, y de eficacias de las prácticas científicas.

El Discurso del Método, es, por eso, un título que debe ser tomado al pie de la letra, pues el Método que ofrece es el método mismo del Discurso, despojado de toda mácula de subjetividad que pueda empañar su eficacia.

\section{El corte había de ser absoluto}

El corte había de ser absoluto:

Yo me propuse arrancar de mi espíritu todas las ideas que me enseñaron [...] (Descartes, 1637:13)

Descartes recusa pues, simultáneamente, todo criterio de autoridad anclado en el pasado, a la vez que todo rasgo pasional que pueda contaminar el discurso - ¿de qué sino de subjetividad? Se trata, dice, de guiarse sólo por los dictados de la razón (Descartes, 1637: 13) pues ésta se manifiesta en los dictados que rigen el buen orden del discurso científico.

Contra la autoridad y las pasiones: seguir el dictado de los significantes.

Emerge así un Yo que, decidido a eliminar todo vestigio del pensamiento mitológico -pues ese es el fundamento de la autoridad del pasado- se propone arrancar -no debería desatenderse la violencia de la expresión escogida: allí donde algo se arranca, se produce un desgarro- de su espíritu todas las ideas que le enseñaron.

Es difícil no encontrar en ello un gesto de la misma índole que aquel otro por el que dos de los príncipes de la Modernidad -Iván El Terrible, Napoleón- rechazaron que el primado de la Iglesia impusiera la corona sobre sus cabezas. Ellos mismos la arrebataron de sus manos en un acto de abierta rebelión contra la autoridad del pasado. Y también: contra la cadena simbólica que constituía, hasta entonces, el fundamento del poder.

Y así, ese nuevo Yo, vacío de esa subjetividad que se constituye en la cadena simbólica que liga al sujeto a su pasado, proclama configurarse a través de la razón misma de los significantes.

\section{Era necesaria una verdad incuestionable}

Ahora bien, para esa fundación filosófica destinada a romper con las confusiones del pasado, era necesario un punto de partida: una verdad incuestionable, cierta e indudable. Algo que, en palabras del propio Descartes, se

\footnotetext{
presente a mi espíritu de manera tan clara y distinta que acerca de su certeza no pudiera caber la menor duda. (Descartes, 1637: 16)
} 
Y bien, si los discursos del pasado son sospechosos, si las impresiones procedentes de lo real pueden engañar y si el sujeto puede ser llevado a error por la imaginación y la voluntad, sólo en el orden de los significantes podrá encontrarse esa ansiada certeza:

Pienso que carezco de sentidos. ¿Qué hay, pues, digno de ser considerado como verdadero? Tal vez una sola cosa: que nada cierto hay en el mundo. (Descartes, 1641: 58)

\section{Matemáticas}

Descartes advierte, con absoluta claridad, que para fundar científicamente los saberes físicos, médicos o astronómicos, es a las matemáticas a donde hay que acudir (Descartes: 1641: 81) ${ }^{4}$ :

El método que enseña a seguir el orden verdadero contiene todo aquello que da certeza a las reglas de la aritmética. (Descartes, 1637: 17)

Por eso, encuentra en ella su punto de partida:

Sólo los matemáticos pudieron hallar algunas demostraciones, es decir, razones ciertas y evidentes, que por lo menos me servirían para acostumbrar a mi espíritu a las verdades demostradas con toda certeza y a rechazar los errores y sus falsas apariencias. (Descartes, 1637: 16)

Dos son los rasgos que confieren a la herramienta matemática su poder: construye enunciados unívocos y los articula en una estructura discursiva caracterizada por su extrema consistencia interna (Descartes, 1641: 46). De ellos se deduce la más notable percepción cartesiana: que lo que permite a las matemáticas alcanzar tal grado de certeza, de indudabilidad, no se debe en ningún caso a su proximidad a lo real -a ese ámbito de lo real que la medicina, la física y la astronomía intentan explorar-, sino, bien por el contrario, a su extrema lejanía: su cualidad mejor estriba por eso en su despreocupación, en su autonomía total con respecto al ámbito de lo real: el de la Naturaleza.

Esto es, pues, lo que Descartes ha percibido en las matemáticas: la vía para aislar y depurar, en el Lenguaje, cierta dimensión de eficacia que es la del orden estructural y sintáctico de los significantes.

Un orden capaz de exhibir su consistencia, su cristalina claridad. Independientemente de toda contingencia del sujeto o de lo real, pues siempre, con independencia de cualquier hecho real, dos $y$ tres son cinco y el cuadrado tiene cuatro lados.

Pues, es tal

El objeto de los geómetras, que nada en él que me asegurase la existencia de su objeto: por ejemplo, un triángulo, era preciso que sus tres ángulos fuesen iguales a dos rectas, pero no por eso veía algo que me diera la seguridad de que en el mundo existía un triángulo.

Cuando imagino un triángulo, aunque tal vez fuera de mi pensamiento no exista esta figura ni haya existido, no deja, sin embargo, de existir cierta naturaleza, forma o esencia determinada, que no he inventado y que no depende en modo alguno de mi espíritu. (Descartes, 1637: 23)

\footnotetext{
${ }^{4} \mathrm{Y}$ también: la física, la astronomía, la medicina y las demás ciencias que dependen de la consideración de las cosas compuestas, son muy dudosas e inciertas; en cambio, la aritmética, la geometría y las otras ciencias análogas, que tratan de cosas muy simples y muy generales, sin preocuparse de si existen o no en la Naturaleza, contienen algo cierto e indudable. Esté despierto o este dormido, dos y tres son cinco y el cuadrado tiene cuatro lados (Descartes, 1641: 56).
} 
El rigor con el que Descartes prosigue su reflexión sobre las matemáticas le conduce, tras haber aislado ese orden de los significantes para el que conviene el nombre de orden semiótico -pues el triángulo sólo existe en cuanto tejido por los significantes de la geometría-, tanto de lo real como del sujeto, lo aísla también de toda implicación imaginaria ${ }^{5}$ :

Si quiero pensar en un kilógono concibo bien que es una figura compuesta de mil lados; pero me es imposible imaginar los mil lados del kilógono como imagino los tres del triángulo. (Descartes, 1641: 81)

Así, diferencia nítidamente Descartes la imaginación -siempre dependiente de las formas figurativas- de la abstracción esencial del entendimiento, en tanto intelección o concepción pura.

Por ello, la revolucionaria conquista cartesiana estriba en la toma de conciencia del aislamiento del significante, una vez desrealizado, desubjetivizado y desimaginarizado, como pura maquinaria de entendimiento, es decir, de abstracción y de formalización.

\section{La duda cartesiana se constituye en el núcleo de toda certeza}

Y así, la duda cartesiana se constituye en el núcleo de toda certeza: que su signo sea negativo que nada cierto hay...- carece de importancia una vez que la certeza se ubica fuera del ámbito de lo real: en ese otro ámbito, en todo autónomo, que es el de los significantes.

Pues no es menor la dignidad matemática de un valor negativo que el de uno positivo:

He llegado a habituarme a separar mi espíritu de los sentidos [...] Por eso me será ahora muy fácil apartar mi pensamiento de la consideración de las cosas sensibles e imaginables, para llevarlo a las puramente inteligibles (Descartes, 1641: 72) ${ }^{6}$.

Así, esta primera certeza cartesiana -pues no debería olvidarse que este nada cierto hay en el mundo es el presupuesto lógico que precede al más famoso pienso, luego existo, como lo demuestra una ulterior formulación que sintetiza en uno esos dos momentos del cogito: dudo, luego soy (Descartes, 1641: 65) - aísla el poder del significante en su autonomía: aun cuando nada haya cierto en el mundo, es cierto que hay una cadena de significantes que articulan que nada hay cierto en el mundo.

Todo se deduce lógicamente de ahí ${ }^{7}$ :

Examiné atentamente lo que era yo, y viendo que podía imaginar que carecía de cuerpo, pero que no podía concebir mi no existencia, porque mi mismo pensamiento de dudar de todo constituía la prueba más evidente de que yo existía - comprendi que yo era una sustancia, cuya naturaleza o esencia era a su vez el pensamiento, sustancia que no necesita ningún lugar para ser ni depende de ninguna cosa material; de suerte que este yo -o lo que es lo mismo, el alma-por el cual soy lo que soy, es enteramente distinto del cuerpo. (Descartes, 1637: 21)

\footnotetext{
${ }^{5}$ La diferencia existente entre la imaginación y la pura intelección o concepción. Por ejemplo: cuando imagino un triángulo no sólo concibo que es una figura compuesta de tres líneas, sino que contemplo estas tres líneas como presentes; a esto llamo propiamente imaginar. (Descartes, 1641: 81)

${ }^{6}$ El entendimiento, por sí solo no asegura ni niega ninguna cosa; concibe las ideas de las cosas que puede afirmar o negar. Considerándole así, nunca encontraremos error en su propia significación. (Descartes, 1641: 74)

${ }^{7}$ Si yo pensaba que todo era falso, yo, que pensaba, debía ser alguna cosa, debía de tener alguna realidad; y viendo que esta verdad: pienso, luego existo era tan firme y tan segura que nadie podría quebrar su evidencia, la recibí sin escrúpulo alguno como el primer principio de la filosofía que buscaba. (Descartes, 1637: 21)
} 
Un Yo, pues, que carece de cuerpo, que existe como puro pensamiento articulado, con independencia de toda contingencia procedente de lo real.

\section{Fundar el ser del sujeto en el plano del entendimiento}

La hiperbólica duda cartesiana, tras vaciar ese campo que es nombrado como el del espíritu de toda conexión con lo real -se trate de lo real exterior como del propio cuerpo en el que ese espíritu habita- conduce de manera inevitable a fundar el ser del sujeto en el plano del entendimiento -en el plano cognitivo, deberíamos decir:

Si yo cesara de pensar, en el mismo momento dejaría de existir [...] Hablando con precisión, no soy más que una cosa que piensa, es decir, un espíritu, un entendimiento, una razón. [...] no soy ese conjunto de miembros llamado cuerpo humano (Descartes, 1641: 60) ${ }^{8}$.

Pero, a diferencia de lo que sucede en la psicología cognitiva contemporánea, en Descartes resulta manifiestamente claro el que ese plano cognitivo es el plano mismo del discurso; pues la duda hiperbólica que ha dejado al margen toda referencia a lo real, ha conducido a anclar la certeza en el campo mismo del lenguaje: porque hay discurso, hay un Yo del discurso, sometido a la coherencia modelizada por la lógica matemática- de sus enunciados.

La vía teórica que así es puesta en marcha, localiza el núcleo rector del sujeto en ese Yo cognitivo, centralmente emplazado con respecto a todas las otras facultades del espíritu, como el imaginar y el sentir.

Lo no cognitivo del sujeto - ese que es el ámbito de la experiencia y de lo real, del cuerpo y de la pasión- se descubre, finalmente, como distinto de mí; como pertenencias diferentes y adheridas a ese Yo cognitivo que localiza su ser como un significante más de la cadena de los significantes ${ }^{9}$.

\section{Mal aprendizaje, disfunción cognitiva}

Y porque la esencia del sujeto -el espíritu- es concebido en una dimensión cognitiva, el cuerpo se descubre como fuente de confusiones que disturban el buen orden del entendimiento ${ }^{10}$.

Por eso, el pecado ha de ser concebido no como otra cosa que un error (Descartes, 1641: 53):

¿Dónde nacen, pues, mis errores? De que siendo la voluntad mucho más amplia y extensa que el entendimiento, no la contengo en los mismos límites, sino que la extiendo a las cosas que no entiendo, se extravía fácilmente y elige lo falso por lo verdadero y el mal por el bien; todo esto hace que yo me equivoque y peque (Descartes: 1641: 76).

\footnotetext{
${ }^{8}$ Soy una cosa que piensa, o una substancia cuya esencia o naturaleza es el pensar. Mi alma, por la cual soy lo que soy, es completa y verdaderamente distinta de mi cuerpo, y puede ser o existir sin él. (Descartes, 1641: 84)

${ }^{9}$ El espíritu o el alma del hombre es enteramente diferente del cuerpo. (Descartes, 1641: 88)

${ }^{10}$ Las maneras confusas de pensar, que dependen y provienen de la unión y como mezcla del espíritu y del cuerpo. (Descartes, 1641: 85)
} 
No estamos lejos de las nociones de mal aprendizaje, de disfunción cognitiva, que la psicología y la sociología del siglo XX movilizarán para pensar el conflicto.

Anticipándose, Descartes advierte ya la necesidad de que la voluntad -única palabra, en el léxico cartesiano, donde puede situarse lo que es propio de la pulsión- pueda someterse a los dictados del entendimiento:

La luz natural nos enseña que el conocimiento del entendimiento debe preceder a la determinación de la voluntad.

En este mal uso del libre arbitrio se encuentra la privación que constituye la forma del error. (Descartes, 1641: 75)

\section{Cuerpo máquina}

Conviene pues recordar que el dualismo cartesiano nada tiene que ver con la dramática entre el cuerpo y el alma -el pecado y la pureza- que caracterizó el pensamiento de siglos anteriores.

Pues aquí no se trata tanto, después de todo, de postular la necesidad de que el espíritu gobierne al cuerpo -ponga límite a sus pasiones- sino de concebir la posibilidad de un dominio neto del entendimiento sobre un cuerpo que, al modo de la moderna psicología cognitiva, es por eso concebido como despulsionalizado -ya no cuerpo pulsional, ya no motor de subjetividad deseante-, sino, a partir de ahora, concebido sobre el modelo racionalista de la máquina y, por eso, potencialmente del todo gobernable: 1641: 76)

Si retengo mi voluntad en los limites de mi conocimiento es imposible que me equivoque. (Descartes,

Después de todo, todo es posible, todo puede solucionarse -normalizarse- con un buen aprendizaje:

Un pensamiento [...], puedo, [...] por una meditación atenta y reiterada, imprimirlo tan fuertemente en la memoria, que siempre me acuerde de él cuando lo necesite, adquiriendo así el hábito de no equivocarme.

Se abre así la vía, con sólo seguir el camino infalible de la ciencia (Descartes, 1637: 34), de un dominio siempre acrecentable del cuerpo y del mundo. Por ello propone Descartes ${ }^{11}$ sustituir la filosofía especulativa por una

Filosofía eminentemente práctica (...) aplicaríamos esos conocimientos a los objetos adecuados y nos constituiríamos en señores y poseedores de la Naturaleza (Descartes, 1637: 33).

El proyecto de la Modernidad ha quedado, pues, formulado.

\footnotetext{
${ }^{11}$ Es posible llegar a la adquisición de conocimientos utilísimos para la vida y que, en lugar de la filosofía especulativa que se enseña en las escuelas, se puede encontrar una filosofía eminentemente práctica, por la cual, conociendo la fuerza y las acciones del fuego, del agua, del aire, de los astros, de los cielos y de todo lo que nos rodea, tan distintamente como conocemos los oficios de nuestros artesanos, aplicaríamos esos conocimientos a los objetos adecuados y nos constituiríamos en señores y poseedores de la Naturaleza (Descartes, 1637: 33).
} 


\section{Pesadilla}

Pero, justo entonces, emerge la pesadilla:

Todo lo que hasta ahora he tenido por verdadero y cierto ha llegado a mi por los sentidos; algunas veces he experimentado que los sentidos engañan; y como del que nos engaña una vez no debemos fiarnos, yo no debo fiarme de los sentidos.

Pero si estos nos inducen a errores algunas cosas en las poco sensibles y muy lejanas, por ejemplo - hay muchas de las cuales no es razonable dudar: que yo estoy aquí, sentado al lado del fuego, con un papel entre las manos, vestido de negro, es cosa indudable para mí. ¿Cómo puedo negar que estas manos y este cuerpo son mios? Para negarlo tendría que ser un insensato o un perturbado [...] Esos son locos y yo sería tan extravagante como ellos si siguiera su ejemplo.

Sin embargo, no he de olvidar que soy hombre y, por consiguiente, que tengo la costumbre de dormir $y$ de representarme en sueños las cosas reales y otras tan inverosímiles y descabelladas como las que se les ocurren a esos insensatos. Cuántas veces he soñado que estaba como ahora, vestido, sentado ante la mesa, junto al fuego, con un papel entre las manos, y sin embargo, dormía en mi lecho.

¿Estaré soñando ahora? [...] Todo me parece mucho más distinto y preciso que en un sueño. No, no estoy soñando.

Pero [...] recuerdo que durmiendo me frotaba los ojos para convencerme de que no estaba soñando, y me hacía las mismas reflexiones que despierto me hago ahora. Eso me ha ocurrido muchas veces. De aqui deduzco que no hay indicios por los que podamos distinguir netamente la vigilia del sueño. [...] ¿será un sueño la vida? (Descartes, 1641: 55-56)

Es difícil no percibir la densidad de la duda cartesiana, es decir, la angustia que en ella late y que motiva, con una intensidad propiamente pulsional, la búsqueda de esa al menos una certeza.

En este apasionante -y apasionado- párrafo de las Meditaciones metafísicas Descartes ya no se desenvuelve tan sólo en el plano especulativo de la reflexión teórica: confiesa, en el origen de su reflexión, una angustiante experiencia de pérdida de realidad; el sueño que describe, tantas veces soñado -Cuántas veces he soñado que estaba como ahora... -, se descubre con la contundencia de la pesadilla repetida que prolonga desmesuradamente sus ecos sobre la vigilia del que la sueña.

¿Cómo, si no, alcanzaría a poner en duda la realidad misma de la vigilia en la que el filósofo escribe, sentado al lado del fuego, con el papel en las manos? A la oscura luz de esta pesadilla cobra una significación suplementaria este enunciado que Descartes formulara más de diez años antes en un rincón del Discurso del Método:

Frecuentemente la imaginación se exalta en el sueño mucho más que en la normalidad de la vida perfectamente consciente (Descartes, 1637: 24).

La intensidad de esa exaltación, por ser mayor que la de la normalidad de la vida perfectamente consciente, penetra en esa misma normalidad consciente amenazándola en profundidad, hendiéndola con una duda angustiosa que alcanza a suspender y que amenaza con desintegrar la realidad del filósofo. 
No puede extrañar entonces que la palabra locura aparezca dos veces escrita: si es invocada como mera referencia de la reflexión teórica, su repetida presencia no deja de confesar el temor por ella que en el texto cartesiano late.

Con ella rima, por lo demás, la idea paranoide de un dios maligno como responsable extremo de esa amenazante disolución de la realidad:

Hay un no sé qué muy poderoso y astuto que emplea toda su industria en engañarme siempre (Descartes, 1641, 12).

Supondré pues que Dios es un genio astuto y maligno que ha empleado su poder en engañarme [...] Prepararé mi espiritu tan bien para rechazar las astucias del genio maligno. (Descartes, 1641: 58)

Que ello es así lo confirman las palabras del propio Descartes cuando confiesa su penar ante las tenebrosas dificultades que le asaltan:

Mi propósito es penoso y difícil; caigo de nuevo en mis antiguas ideas, temiendo que las vigilias laboriosas que han de suceder a la tranquilidad de mi vida reposada, en lugar de proporcionarme alguna luz en el conocimiento de la verdad, sean insuficientes para aclarar las tenebrosas dificultades que acabo de remover (Descartes: 1641: 58).

¿Remover significa aquí eliminar? ¿Quizás apartar? Pero, ¿por qué no agitar? En todo caso es el propio Descartes quien describe el color de la vivencia que le asalta a través de una siniestra imagen: como si hubiera caido en un pozo [...] (Descartes: 1641: 58)

De manera que ninguna coquetería escéptica anima la escritura cartesiana; todo en ella empuja a suprimir la duda para así exorcizar la angustia que la acompaña:

No es que imitara yo a los escépticos que dudan por dudar [...] sino que al contrario, buscaba tierra firme, base sólida en qué fundar las afirmaciones de mi fe científica (Descartes, 1637: 20)

Pues el espesor del sueño sigue con todo ahí, por más que, en un gesto final cuya premura delata su carácter endeble, trata de negar su amenaza:

Debo rechazar las dudas de estos días pasados como hiperbólicas y ridiculas, particularmente esa inseguridad tan general relativa al sueño que no podía distinguir de la vigilia; porque encuentro una diferencia muy grande: nuestra memoria no puede enlazar unos sueños con otros ni con el resto de la vida, y en cambio puede enlazar las cosas que nos ocurren estando despiertos (Descartes: 1641: 89).

Es fácil evidenciar, con las mismas herramientas cartesianas, la fragilidad de esta conclusión apresurada: pues esas pesadillas no necesitan ser enlazadas de otra manera que como ellas mismas se enlazan: por esa vía, después de todo la más directa, que es la de la repetición: eso me ha ocurrido muchas veces.

Y es que, si la realidad desaparece, con ella desaparece el tiempo, la sucesión en la que existen cosas que deben ser enlazadas. 
Pero si esta huida hacia delante con la que Descartes concluye sus Meditaciones metafísicas en nada debilita el rigor de su discurso, es porque el obstáculo planteado por la indefinición de los confines que separan al sueño de la vigilia había podido ser resuelto anteriormente de una manera mucho más elegante -y por eso más propiamente cartesiana.

Y ello porque lo que hubo de resolverse no era esa inquietante indefinición, sino tan sólo su capacidad de obstaculizar el camino mismo de la configuración de su Método.

Lo hemos advertido: el núcleo de la certeza cartesiana se formulaba -al igual, dicho sea de paso, que el significante saussuriano y que la proposición elemental wittgensteiniana-, en términos negativos: se trataba de la evidencia de que nada cierto hay en el mundo.

$\mathrm{Y}$ es que la certeza sólo debe ser buscada en el ordenamiento mismo de los significantes de acuerdo con sus propias reglas.

Y bien: esas reglas, esos encadenamientos de enunciados, demuestran estar presentes no sólo en la vigilia, sino también en el sueño, como lo demuestra el sueño del geómetra:

Puede ocurrir que soñando nos venga a la mente una idea muy clara, por ejemplo: un geómetra que encuentra una nueva demostración. En este caso, el sueño del geómetra no impedirá que su idea sea verdadera (Descartes, 1637: 24).

O, como el mismo Descartes señalaba en otro lugar: 1641: 56)

Esté despierto o esté dormido, dos y tres son cinco y el cuadrado tiene cuatro lados [...] (Descartes,

Por eso,

Lo mismo despiertos que dormidos nunca debemos persuadirnos más que por la evidencia de nuestra razón. Observad que digo evidencia de nuestra razón y no de nuestra imaginación ni de nuestros sentidos. (Descartes, 1637: 24)

Y así, si la incertidumbre que el sueño -y la pesadilla- deposita en la conciencia no queda por ello resuelta, la evidencia de los significantes de la razón cartesiana puede manifestarse, ante ello, indiferente: sean cuales sean las cualidades que distinguen al sueño de la vigilia, tanto como a las confusiones que entre ambos estados puedan manifestarse, los significantes de la ciencia podrán seguir caminando de acuerdo con sus propias reglas.

El Método de la Ciencia sobre el que se funda la racionalidad de la Modernidad, encuentra así su indiscutible fundamento. Pero, a la vez, en ese mismo movimiento, el individuo, la radical singularidad real de su ser, queda desprendido de ese Método y de esa Racionalidad. Condenado -pues carente de toda palabra densa, vivible como verdadera, capaz, en suma, de permitirle afrontar lo real- 
20 Tropelías. Revista de Teoría de la Literatura y Literatura Comparada, 31 (2019) Jesús González Requena

a esa pesadilla que constituye la otra cara de la Modernidad -pues los fantasmas de la razón crean monstruos- para la que hace tiempo venimos proponiendo el nombre de Posmodernidad.

\section{Referencias bibliográficas}

Descartes, R. (1637): Discurso del Método, Porrúa, México, 1972.

- (1641): Meditaciones metafisicas, Porrúa, México, 1972. 